\section{(1)}

CrossMark

\title{
Omalizumab reduces bronchial mucosal IgE and improves lung function in non-atopic asthma
}

\author{
Prathap Pillai ${ }^{1}$, Yih-Chih Chan ${ }^{1}$, Shih-Ying Wu ${ }^{1}$, Line Ohm-Laursen ${ }^{1}$, \\ Clare Thomas ${ }^{1}$, Stephen R. Durham² ${ }^{2}$, Andrew Menzies-Gow ${ }^{2}$, \\ Raj K. Rajakulasingam ${ }^{3}$, Sun Ying ${ }^{1}$, Hannah J. Gould ${ }^{1}$ and Chris J. Corrigan ${ }^{1}$
}

Affiliations: ${ }^{1}$ Dept of Respiratory Medicine and Allergy, and Randall Division of Cell and Molecular Biophysics, King's College London, London, UK. 'Section for Allergy and Clinical Immunology at NHLI, Imperial College London, London, UK. ${ }^{3}$ Dept of Respiratory Medicine and Allergy, Homerton University Hospital NHS Foundation Trust, London, UK.

Correspondence: Prathap Pillai, Dept of Respiratory Medicine and Allergy, MRC-Asthma UK Centre for Allergic Mechanisms of Asthma, Division of Asthma, Allergy and Lung Biology, (King's College, London) 5th Floor, Tower Wing, Guy's Hospital, London, United Kingdom, SE1 9RT. E-mail: prathap.pillai@kcl.ac.uk

ABSTRACT Omalizumab therapy of non-atopic asthmatics reduces bronchial mucosal IgE and inflammation and preserves/improves lung function when disease is destabilised by staged withdrawal of therapy.

18 symptomatic, non-atopic asthmatics were randomised (1:1) to receive omalizumab or identical placebo treatment in addition to existing therapy for 20 weeks. Bronchial biopsies were collected before and after 12-14 weeks of treatment, then the patients destabilised by substantial, supervised reduction of their regular therapy. Primary outcome measures were changes in bronchial mucosal $\operatorname{IgE}^{+}$cells at $12-14$ weeks, prior to regular therapy reduction, and changes in lung function (forced expiratory volume in $1 \mathrm{~s}$ ) after destabilisation at 20 weeks. Quality of life was also monitored.

Omalizumab but not placebo therapy significantly reduced median total bronchial mucosal $\mathrm{IgE}^{+}$cells $(\mathrm{p}<0.01)$ but did not significantly alter median total mast cells, plasma cells, B lymphocytes, eosinophils and plasmablasts, although the latter were difficult to enumerate, being distributed as disperse clusters. By 20 weeks, lung function declined in the placebo-treated patients but improved in the omalizumab treated patients, with significant differences in absolute $(\mathrm{p}=0.04)$ and $\%$ predicted forced expiratory volume in $1 \mathrm{~s}$ $(\mathrm{p}=0.015)$.

Omalizumab therapy of non-atopic asthmatics reduces bronchial mucosal $\operatorname{IgE}^{+}$mast cells and improves lung function despite withdrawal of conventional therapy.

@ERSpublications

Omalizumab reduces mucosal IgE and improves lung function in non-atopic asthma http://ow.ly/CHFu3034fcC

Editorial comment in Eur Respir J 2016; 48: 1538-1540.

This article has supplementary material available from erj.ersjournals.com

Received: Sept 092015 | Accepted after revision: Aug 03 2016 | First published online: Oct 202016

Clinical trial: This study is registered at clinicaltrials.gov with identifier number NCT01113437.

Support statement: This study was supported by research grants from i) Guy's and St. Thomas' Charity and ii) Novartis UK. The authors acknowledge financial support from the Department of Health via the National Institute for Health Research (NIHR) comprehensive Biomedical Research Centre award to Guy's \& St Thomas' NHS Foundation Trust in partnership with King's College London and King's College Hospital NHS Foundation Trust. Funding information for this article has been deposited with the Open Funder Registry.

Conflict of interest: Disclosures can be found alongside this article at erj.ersjournals.com

Copyright OERS 2016 


\section{Introduction}

Asthma remains a leading cause of suffering worldwide [1]. In the UK, an estimated $10 \%$ of the 5.2 million sufferers remain symptomatic and vulnerable to exacerbations [2]. The humanised, monoclonal $\mathrm{IgG}_{1}$ anti-IgE antibody omalizumab is the vanguard of an arsenal of new biologicals purposed to improve the lives of severe asthma sufferers. Its clinical effectiveness in a substantial proportion of severe asthmatics is now acknowledged by relevant bodies worldwide, including the British Thoracic Society (BTS) and The National Institute for Health and Care Excellence [3] in the UK.

A major challenge when deploying treatment with biologicals for severe asthma is the possibility of mechanistic variation in the disease, requiring pre-identification of potential responders to any specific agent. In the case of omalizumab, the prima facie effect of which is to prevent binding of IgE to its highand low-affinity receptors $[4,5]$, the tacit assumption has been that it improves asthma stability fundamentally by reducing or abolishing mast cell and basophil activation by cross-linking of surface-bound allergen-specific IgE by allergen in suitably sensitised, "atopic" patients. Consequently, key clinical trials investigating its efficacy, such as INNOVATE (The INvestigatioN of Omalizumab in seVere Asthma TrEatment (INNOVATE) study) [6] have been limited to atopic asthmatics while its marketing authorisation restricts its use to patients with "convincing IgE-mediated asthma". This phrase is not universally defined but is in practice usually equated with evidence of IgE sensitisation (by skin prick or in vitro testing) to one or more common perennial aeroallergens. Conversely, the therapy has been denied to at least, we estimate, 20000 otherwise eligible non-atopic severe asthmatics in the UK, and many more worldwide (the prevalence of non-atopic, severe asthma was estimated at $50 \%$ of the total in the ENFUMOSA (European Network For Understanding Mechanisms Of Severe Asthma) study [7] and $17-34 \%$ in the SARP (Severe Asthma Research Programme) study) [8].

Much indirect evidence suggests that IgE may play a role in asthma regardless of conventional atopic status. Epidemiologically, asthma was five-fold more prevalent in a cohort of non-atopic subjects with elevated total serum IgE [9]. We and others have shown that atopic and non-atopic asthma are virtually identical in terms of their bronchial mucosal cellular and molecular immunopathology [10-17], evidence of local B cell switching to IgE synthesis $[18,19]$ and elevated local FceRI receptor expression [20] and total bronchial mucosal IgE concentrations [21]. Furthermore, IgE directed against antigens other than aeroallergens, such as viral antigens [22] and Staphylococcal enterotoxins [23] has been implicated in asthma pathogenesis. IgE may influence mast cell function by antigen-independent mechanisms [24, 25] and theoretically exacerbate asthmatic bronchial mucosal inflammation by mechanisms not involving mast cells and basophils, such as by enhancing antigen capture [26]. All of these data lend weight to the view that the presence or absence of atopy as operationally defined might not be an appropriate criterion for predicting responsiveness to omalizumab therapy.

Consequently, we elected in a proof-of-concept study to address the hypotheses that omalizumab therapy of non-atopic asthmatics reduces the numbers of $\operatorname{IgE}^{+}$leukocytes (B cells, plasmablasts and mast cells) within the bronchial mucosa of the target organ and exerts a favourable effect on lung function in the short term, as assessed by changes in forced expiratory volume in $1 \mathrm{~s}$ (FEV1). To accomplish this, we obtained bronchial biopsies from the patients before and after a 12-14 week course of treatment with omalizumab or placebo while maintaining their current therapy and evaluated mucosal $\operatorname{IgE}^{+}$cell numbers as a co-primary outcome measure. We then destabilised the patients over a further 6-8 week period, while maintaining omalizumab/placebo therapy, by staged reduction of existing anti-asthma therapy according to a protocol powered to detect changes in FEV1, the primary outcome measure.

\section{Study design, patients and laboratory methods}

Study design

This was a randomised, placebo-controlled, double-blind, parallel-group, proof-of-concept study of 20 weeks' duration. Omalizumab and identical vehicle control manufactured to good clinical practice standards were kindly supplied by the manufacturers (Novartis, Basel, Switzerland). The trial was approved and monitored by Guy's Research Ethics Committee (REC Ref: 09/H0804/43) and the Medicines and Healthcare Products Regulatory Agency (CTA No: 14523/0219/001/0001) and registered on clinicaltrials. gov (reference NCT01113437). Eligible patients were uncontrolled, non-atopic asthmatics who provided written, informed consent recruited from the asthma clinics at Guy's and St. Thomas', the Royal Brompton and the Homerton University Hospitals in London, UK.

Asthma was defined as a history of relevant symptoms and documented. i) $\geqslant 12 \%$ reversibility of FEV 1 in response to inhaled bronchodilator and/or ii) $\geqslant 8 \%$ variability of the peak expiratory flow during a $24 \mathrm{~h}$ period or $\geqslant 20 \%$ variability over a period of $1-2$ weeks. Uncontrolled disease was defined as regular (at least 3 days per week) day- and night-time symptoms in the 3 months prior to screening despite regular step 3-5 asthma treatment according to the BTS guidelines. Non-atopic was defined as negative skin prick 
and/or in vitro IgE tests (Grade 0 or $\leqslant 0.35 \mathrm{kU} \cdot \mathrm{L}^{-1}$, ImmunoCAP, Phadia, Uppsalla, Sweden) to the following local UK aeroallergens: mixed grass, mixed tree, mixed mould, cat, dog and house dust mite. The non-atopic status of these participants was further confirmed by full immuno-solid phase allergen chip (ISAC;Phadia) screening of their sera and bronchial biopsy homogenates (data presented elsewhere) [21]. Exclusion criteria are listed in the supplementary material.

The phases of the study protocol are summarised in figure 1 .

\section{Screening/baseline}

After providing written, informed consent, during a baseline period of up to 4 weeks, patients were assessed for compliance with the inclusion/exclusion criteria and prepared for future visits. Existing anti-asthma medication was not changed but compliance encouraged.

\section{First bronchoscopy and commencement of therapy}

At a second visit patients completed a Juniper Asthma Control Questionnaire (ACQ) [27] and mini-Asthma Quality of Life Questionnaire (mini-AQLQ) [28], then underwent pre-bronchodilator spirometry (Minispir PC-based Spirometer, Winspiro Pro version 4.1.5 software; MIR, Rome, Italy) prior to the obtaining of 10 technically suitable bronchial mucosal biopsies from the right or left second- or third-generation bronchi at fibreoptic bronchoscopy using an Olympus bronchoscope model BF XT40 OES (Olympus, Tokyo, Japan). Patients then received their first subcutaneous injection of the trial medication (omalizumab or identical placebo, allocated by the hospital pharmacy using randomisation tables with the patient and attending physician blinded), the dosage and frequency of which (either 2 or 4 weekly) were determined as in standard clinical practice based on their initial body weight and serum total IgE concentration as described in the omalizumab summary of product characteristics. Where serum total IgE was below the lowest concentration in the summary of product characteristics dosing table we administered the lowest dosage in the table (75 $\mathrm{mg}$ every 4 weeks). Patients were observed for $2 \mathrm{~h}$ afterwards. At each subsequent dosing visit, patients were examined clinically and encouraged to comply with their usual medication.

\section{Second bronchoscopy}

Within a 2 week window between 12 and 14 weeks after commencement of omalizumab/placebo therapy (time A, figure 1), lung function was re-measured and repeat bronchial biopsies obtained as before.

\section{Therapy reduction phase}

Patients were instructed carefully how to use a Turbohaler device (AstraZeneca, London, UK) and asked, commencing the day following the second bronchoscopy, to discontinue all existing inhaled and oral anti-leukotriene or theophylline based anti-asthma medications and substitute them with regular budesonide/ formoterol combination therapy (Symbicort 100/6 Turbohaler 2 puffs twice daily initially for 4 weeks and further reduced to 1 puff twice daily until the end of the study) with additional terbutaline (Bricanyl Turbohaler (AstraZeneca) $500 \mu \mathrm{g}$ per puff) as required for immediate relief of symptoms. For patients taking regular additional oral prednisolone, an attempt was also made progressively to reduce the dosage according to a predetermined regimen depending on the dosage at entry to the study (supplementary table E1). Omalizumab/ placebo therapy was continued for a total of 20 weeks while this new therapeutic regimen was pursued.

\section{End of the study}

At their penultimate visit, 20 weeks from commencement of omalizumab/placebo therapy (time B, figure 1), patients completed final ACQ and mini-AQLQ questionnaires then underwent repeat spirometry before



FIGURE 1 Clinical trial flow chart outlining interventions. Baseline: time from screening visit to first bronchoscopy and commencement of omalizumab/placebo (weeks -4 to 0 ); time A: time span during which the patients had a second bronchoscopy (weeks 12-14) after which therapy was reduced; time B: end of the trial 20 weeks from the first injection of omalizumab/placebo. ACQ: Asthma Control Questionnaire; miniAQLQ: mini-Asthma Quality of Life Questionnaire. 
being asked to resume their original anti-asthma therapy. A final visit was arranged 2 weeks later to check the patients' wellbeing and enquire about any adverse reactions.

At any time during the study, in the event of an asthma exacerbation, defined as a need for rescue oral corticosteroid medication for deterioration of symptoms and/or lung function, as agreed between the patient and the study physician, patients were treated with a 10-day course of prednisolone $30 \mathrm{mg} \cdot \mathrm{day}^{-1}$ instituted by the study physician. Such patients left the study, resumed their regular anti-asthma medication and were followed up as necessary.

\section{Immunofluorescence}

Bronchial biopsies were processed and analysed using double or single immunofluorescence, single immunohistochemistry and confocal microscopy where appropriate according to our established protocols described in the supplementary material. Biopsy sections were analysed objectively by operators ignorant of their provenance.

\section{Powering}

In a previous therapy reduction study (CQAE397A2202) performed by Novartis in a similar patient group, the standard deviation of the differences in FEV1 before and after reduction of inhaled corticosteroid was found to be 9.550 . Using 20 subjects per group, this would give a $90 \%$ chance of detecting a $10 \%$ difference, with an alpha of 0.1 using a two-sided test. An investigator blinded interim analysis of differences in FEV1, the primary outcome measure, following recruitment of 18 patients indicated a significant improvement in FEV1 in the omalizumab, but not the placebo-treated group supporting our hypothesis, and so the study was terminated at this stage. Changes in numbers of $\operatorname{IgE}^{+}$cells, the co-primary outcome measure, were unprecedented and so could not be formally powered.

\section{Statistical analysis}

Baseline characteristics and demographic data were summarised using descriptive statistics. Changes in numerical variables at the beginning and end of the study as well as differences in changes between the omalizumab and placebo-treated groups were analysed by non-parametric statistics (Mann-Whitney U-test, Wilcoxon rank sum test). All tests were two sided and a p-value $<0.05$ was considered significant. The statistical software package used was GraphPad Prism version 5 (GraphPad Software, San Diego, CA, USA).

\section{Results}

Patients

The patients randomised to omalizumab or placebo were well matched in terms of distributions of age, sex, body mass index, serum total IgE concentrations, smoking history, lung function, asthma symptom scores and inhaled corticosteroid dosages (table 1). Inhaled corticosteroid dosages were reduced in both groups to $400 \mu \mathrm{g} \cdot \mathrm{day}^{-1}$ beclometasone equivalent between $12-14$ weeks and further to $200 \mu \mathrm{g} \cdot \mathrm{day}^{-1}$ between 16 and 20 weeks. In the omalizumab versus placebo-treated groups, seven versus eight patients were taking long-acting $\beta_{2}$-agonist, four versus one were taking oral leukotriene receptor antagonist and two versus two were taking oral theophylline preparations. All these were stopped or substituted at time A (figure 1). One patient randomised to omalizumab and three to placebo were taking oral prednisolone at dosages of $15 \mathrm{mg} \cdot \mathrm{day}^{-1}$ and 15,10 and $5 \mathrm{mg} \cdot \mathrm{day}^{-1}$ respectively which were reduced to $7.5 \mathrm{mg} \cdot \mathrm{day}^{-1}$ and $7.5,5$ and $0 \mathrm{mg} \cdot \mathrm{day}^{-1}$ respectively according to the predetermined regimen (supplementary table E1). Of 18 patients randomised, 15 completed the study. One patient allocated to placebo and two to omalizumab withdrew prematurely (see Discussion section).

\section{Airways inflammation}

The median numbers of tryptase ${ }^{+}$mast cells, CD $20^{+} \mathrm{B}$ cells, $\mathrm{CD} 138^{+}$plasma cells, CD $38^{+}$plasmablasts, total $\mathrm{IgE}^{+}$cells, $\mathrm{IgE}^{+} /$tryptase $^{+}$mast cells, $\mathrm{IgE}^{+} / \mathrm{CD}^{2} 0^{+} \mathrm{B}$ cells, $\mathrm{IgE}^{+} / \mathrm{CD} 138^{+}$plasma cells, and Barkans Moqbel Kay-13 (BMK-13 ${ }^{+}$) eosinophils per unit area of the bronchial biopsy sections just prior to commencement of omalizumab and at time A (after 12-14 weeks of omalizumab or placebo therapy with no alteration of existing medications, see figure 1) are shown in table 2, while selected changes are depicted graphically in figure 2 . We observed a significant reduction in the median total $\operatorname{IgE}^{+}$cells $(\mathrm{p}<0.001)$, the co-primary outcome measure, in the bronchial mucosa in the patients treated with omalizumab but not placebo. No significant changes were observed in median numbers of any of the other cells analysed following omalizumab or placebo therapy. Very few of the B cells and plasma cells showed detectable $\operatorname{IgE}$ immunoreactivity as expected (table 2), so it was impracticable to evaluate changes. Clusters of CD $38^{+}$ plasmablasts and $\mathrm{CD} 20^{+} \mathrm{B}$ cells were detected in approximately one in every 10 sections of the mucosa (figure $2 \mathrm{f}$ ) but again these were insufficient in number to quantify possible changes. 
TABLE 1 Baseline demographics and clinical characteristics of non-atopic asthmatics randomised to omalizumab or placebo therapy and absolute changes from baseline at times $A$ and $B$

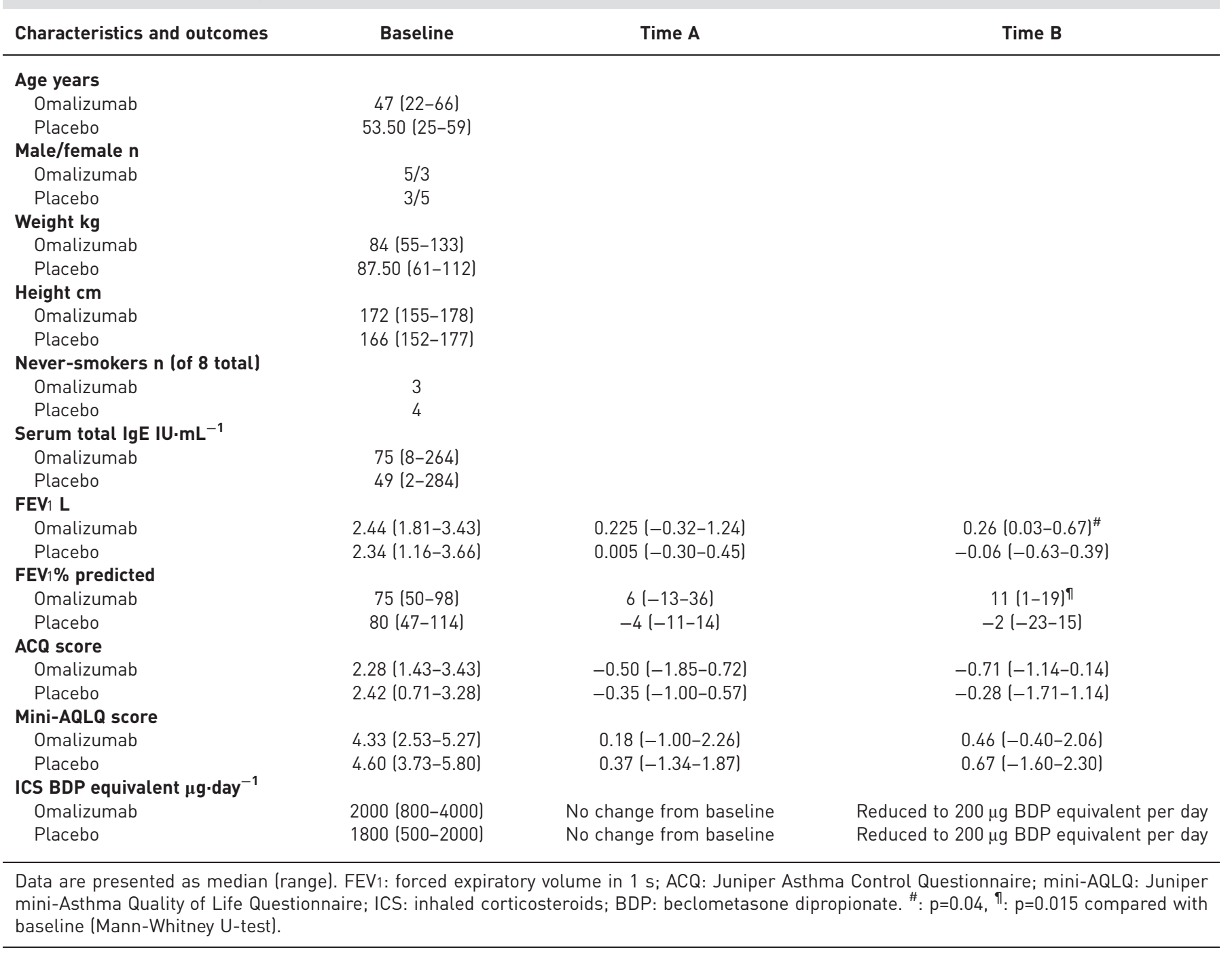

\section{Lung function and asthma symptom scores}

The primary outcome measure in this study was the change in median FEV1 in the omalizumab compared with the placebo treated patients during the study (between baseline and time B in figure 1). The median absolute and \% predicted FEV1 improved during this period in the omalizumab treated patients, despite substantial reduction of existing therapy, but deteriorated in the placebo-treated patients as anticipated (median (semi-interquartile range) change $0.26(0.07-0.64)$ versus $-0.06(-0.14-0.27) \mathrm{L} ; \mathrm{p}=0.04 ; 11(2-18)$ versus $-2.0(-11-1.5) \%$ predicted; $\mathrm{p}=0.015$; see figure 3$)$. As an exploratory measure, we also recorded asthma symptom scores. As shown in table 1, the median ACQ score between baseline and 20 weeks (time B) improved by what is regarded as a clinically meaningful degree in the patients randomised to omalizumab but not placebo despite the staged reductions in existing therapy, although the differences between the groups did not attain statistical significance. In contrast, median mini-AQLQ scores improved to a similar extent in both groups.

\section{Discussion}

We conceived this study to challenge, in the light of current knowledge, the tacit assumption that omalizumab therapy is of no clinical benefit in conventionally defined, non-atopic asthmatics. In lieu of a large, long-term, conventional clinical trial in the first instance, which would have been difficult to fund given the paucity of supportive evidence, we elected to provide proof of concept that omalizumab therapy of these patients reduces IgE expression and IgE sensitisation of target cells within the bronchial mucosa while exerting a favourable effect on lung function in the short term, as assessed by changes in FEV1. We 
TABLE 2 Bronchial mucosal inflammatory cells: absolute counts per $\mathrm{mm}^{2}$ at baseline and absolute changes at time A following treatment with omalizumab or placebo

\begin{tabular}{|c|c|c|}
\hline Cell type & $\begin{array}{l}\text { Absolute numbers } \\
\text { per } \mathrm{mm}^{2} \text { at baseline }\end{array}$ & $\begin{array}{l}\text { Difference between } \\
\text { baseline and time A }\end{array}$ \\
\hline \multicolumn{3}{|c|}{ Tryptase $^{+}$mast cell } \\
\hline Omalizumab & $7.22(0-124.77)$ & $10.88(-61.64-57.70)$ \\
\hline Placebo & $29.92(4.32-75.64)$ & $3.68(-14.66-13.08)$ \\
\hline \multicolumn{3}{|l|}{$\mathrm{CD}^{2} \mathrm{O}^{+} \mathrm{B}$ cell } \\
\hline Omalizumab & $1.48(0.00-9.67)$ & $0.00(-8.25-4.80)$ \\
\hline Placebo & $2.10(0.29-9.35)$ & $-0.15(-1.32-6.39)$ \\
\hline \multicolumn{3}{|c|}{$\mathrm{CD}^{138^{+}}$plasma cell } \\
\hline Omalizumab & $0.00(0.00-36.63)$ & $0.00(-4.42-3.47)$ \\
\hline Placebo & $1.68(0.00-6.80)$ & $-0.24(-1.93-1.13)$ \\
\hline \multicolumn{3}{|c|}{$\mathrm{CD} 8^{+}$plasmablast } \\
\hline Omalizumab & $3.91(0.00-14.57)$ & $3.07(-3.83-69.72)$ \\
\hline Placebo & $0.61(0.00-39.39)$ & $-0.21(-28.39-8.67)$ \\
\hline \multicolumn{3}{|l|}{$\lg E^{+}$cell } \\
\hline Omalizumab & $12.38(1.22-175.90)$ & $-5.44(-109.89--1.30)^{* *}$ \\
\hline Placebo & $16.45(2.86-60.92)$ & $4.98(-17.08-17.81)$ \\
\hline \multicolumn{3}{|l|}{$\operatorname{lgE}^{+}$mast cell } \\
\hline Omalizumab & $9.19(0.00-124.46)$ & $-1.89(-99.94-33.31)$ \\
\hline Placebo & $26.16(4.32-50.23)$ & $7.88(-17.58-24.08)$ \\
\hline \multicolumn{3}{|l|}{$\lg \mathrm{E}^{+} \mathrm{B}$ cell } \\
\hline Omalizumab & $0.00(0.00-0.28)$ & $0.00(0.00-0.32)$ \\
\hline Placebo & $0.00(0.00-0.00)$ & $0.00(0.00-0.00)$ \\
\hline \multicolumn{3}{|l|}{$\operatorname{lgE}^{+}$plasma cell } \\
\hline Omalizumab & $0.00(0.00-5.98)$ & $0.00(-5.41-0.00)$ \\
\hline Placebo & $0.00(0.00-0.46)$ & $0.00(-0.46-0.00)$ \\
\hline \multicolumn{3}{|c|}{ BMK-13+ eosinophil } \\
\hline Omalizumab & 9.03 (2.92-17.20) & $-0.76(-14.40-4.47)$ \\
\hline Placebo & $4.26(0.31-21.36)$ & $0.81(-9.65-7.57)$ \\
\hline
\end{tabular}

Data are shown as the median and range. BMK-13: Barkans Moqbel Kay-13. ${ }^{* *}: p<0.01$.

obtained bronchial biopsies before and after 12-14 weeks of treatment with omalizumab or placebo while maintaining existing therapy, reasoning that any differences in mucosal cell populations between the active and placebo cohorts observed under these conditions would be attributable to omalizumab. We set changes in mucosal $\operatorname{IgE}^{+}$cells as a co-primary outcome measure, although we were unable to power the study to detect such changes a priori because of lack of any pre-existing data. To obtain proof of concept that omalizumab can improve lung function, we then destabilised the patients by staged reduction of their therapy according to a protocol previously validated by Novartis and powered to detect changes in FEV1. Although we failed to recruit 40 patients as suggested by the original power calculation (recruitment of patients with severe asthma willing to undergo two bronchoscopic procedures followed by supervised reduction of their existing therapy and attend 10 study visits over a period of 6 months was a considerable challenge), we were able to demonstrate with considerably fewer patients a clear and statistically significant effect of omalizumab but not placebo in improving FEV1 within a time frame used to gauge responsiveness clinically. In fact, all of the patients treated with omalizumab improved their FEV1 over the 20 week period of the study, despite substantial reduction of their existing therapy. We also explored changes in quality of life and, although the study was not powered to examine these it revealed further intriguing data, particularly an improvement in ACQ score, which is arguably more reflective of short-term asthma stability than mini-AQLQ, which may improve in response to increased surveillance in the context of a clinical trial. These data are congruent with a previous, ground breaking, placebo-controlled proof-of-concept clinical trial by GARCia et al. [29] examining the clinical effects of omalizumab in non-atopic asthmatics, who were also able to demonstrate improvement of FEV1 in their patients and a trend towards improvement in global evaluation of clinical effectiveness and asthma exacerbation rate.

Two patients randomised to omalizumab therapy withdrew, the first following an exacerbation just after commencing omalizumab and prior to any change in therapy. The second patient elected to withdraw during the therapy reduction phase despite lack of any objective evidence of deterioration. The data from this patient's bronchial biopsies, but none of the clinical data were included in the final analysis. One patient assigned to placebo withdrew immediately following screening. Although in larger studies 
a)

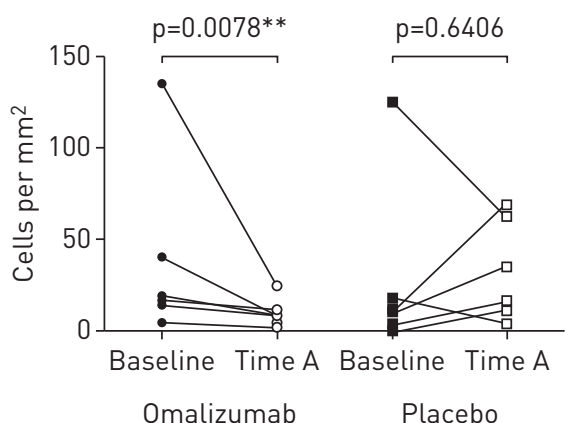

d)

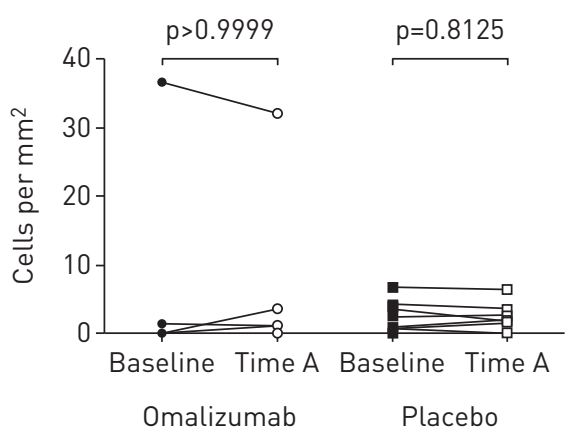

b)

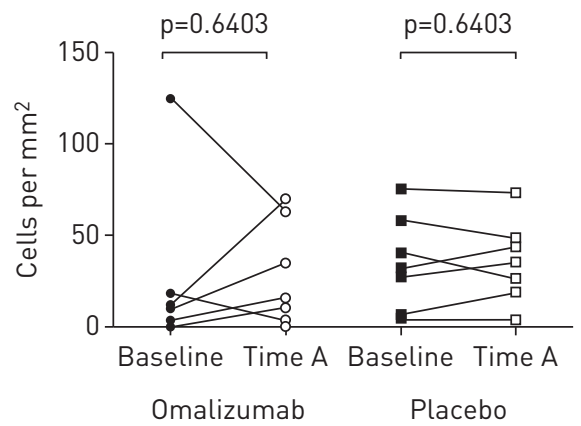

e)

CD38+ plasmablasts

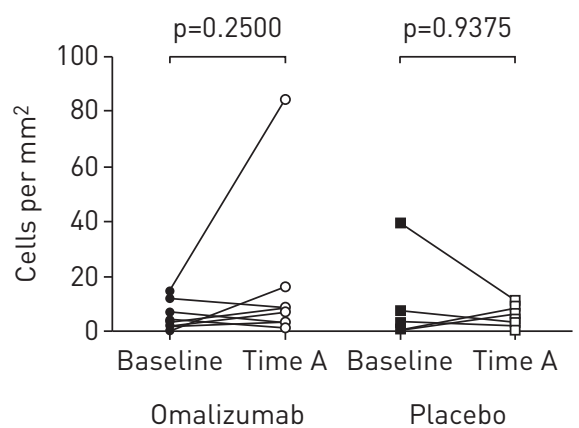

c)

$\lg \mathrm{E}^{+} /$mast cells

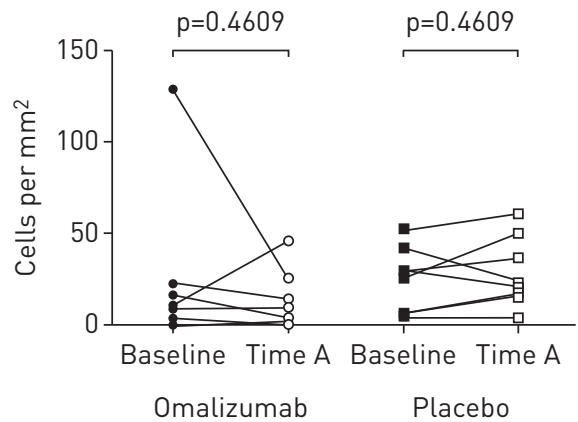

f)

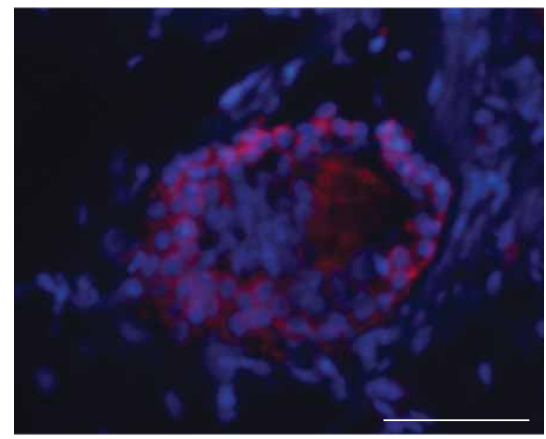


tryptase ${ }^{+}$mast cells; d) $\mathrm{CD}_{138^{+}}$plasma cells; el $\mathrm{CD} 8^{+}$plasmablasts. Wilcoxon rank sum test used for comparison. f) Germinal centre-like follicle of $\mathrm{CD}_{38^{+}}$plasmablasts (red) counterstained with nucleoprotein (blue). Scale bar $=50 \mu \mathrm{m}$

withdrawal rates may reflect the efficacy of a novel therapy, this is clearly not applicable in the present study. One patient assigned to omalizumab and three to placebo were taking oral corticosteroids. Since we hypothesised that omalizumab reduces IgE expression in the target organ of non-atopic asthmatics whose existing therapy is maintained, and that omalizumab therapy preserves/improves FEV 1 in the face of significant therapy reduction, it is unlikely that our conclusions have been influenced by this.

Having demonstrated that IgE is increased in the bronchial mucosa of non-atopic asthmatics [21], we here additionally show that omalizumab therapy substantially reduces the numbers of cells exhibiting associated IgE, consistent with our hypothesis. This presumably reflects sequestering by omalizumab of free $\operatorname{IgE}$
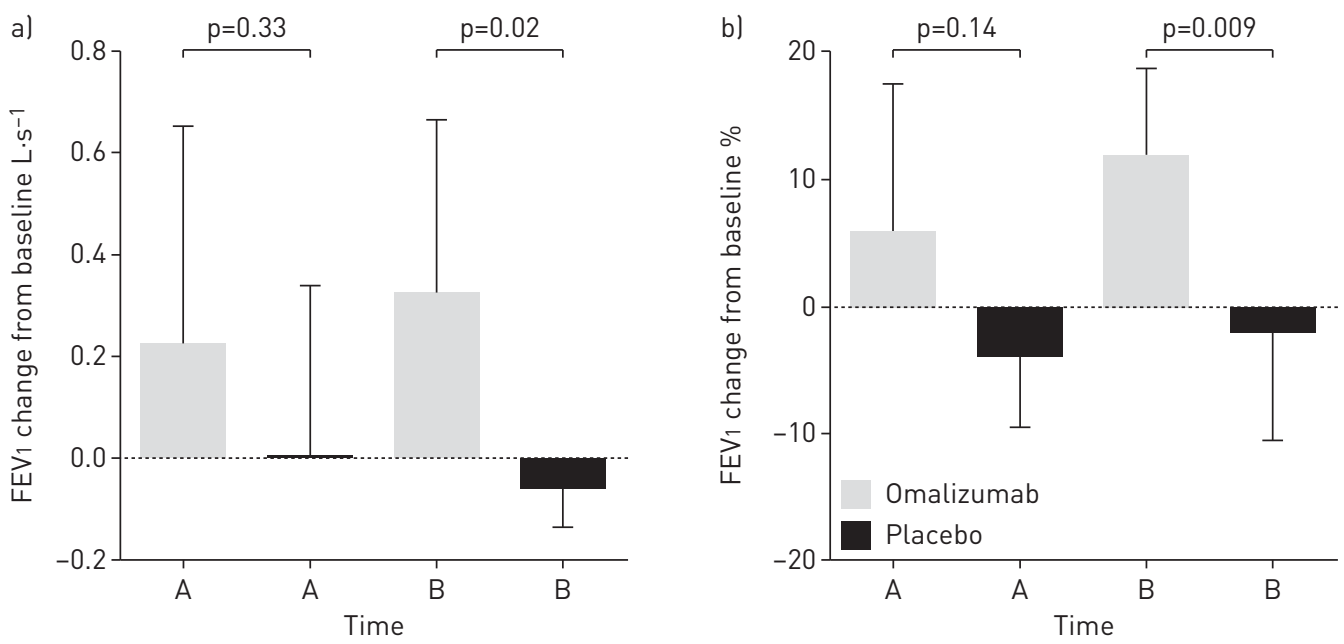

FIGURE 3 Comparison of effect of treatment with omalizumab and placebo on changes in absolute and \% predicted forced expiratory volume in $1 \mathrm{~s}\left(\mathrm{FEV}_{1}\right)$ between baseline and times $\mathrm{A}$ and $\mathrm{B}$. Bars represent the median and interquartile range. Mann-Whitney U-Test used for comparison. 
within the bronchial mucosa, resulting in down regulation of its receptors on local target cells [30-32]. Similarly, in a study of mild atopic asthmatics [33], treatment with omalizumab reduced numbers of bronchial mucosal $\mathrm{FcERI}^{+}$and $\mathrm{IgE}^{+}$cells. Although this is the only clearly described anti-inflammatory activity of omalizumab, there is little understanding of its functional consequences for asthma severity and control, especially in a setting of non-atopic disease. Indeed, in the absence of a clear correlation between down regulation and $\mathrm{IgE}^{+}$cells and clinical efficacy in the omalizumab-treated patients in our study, it is possible to hypothesise that this effect is epiphenomenal and not relevant to amelioration of asthma. It is well established that the clinical effectiveness of omalizumab varies in individual patients in a manner not predicted by their baseline, circulating IgE concentrations [34], suggesting that responsiveness does not simply reflect overall IgE production (at least in the circulation). In addition, CHANEz et al. [35] showed that, while in a group of severe atopic asthmatics omalizumab therapy reduced expression of FceRI on blood basophils and plasmacytoid dendritic cells (a finding also confirmed in the study by GARCIA et al. [29]), there was no correlation with clinical responsiveness.

To further explore possible functional consequences of omalizumab therapy we looked for changes in inflammatory cell numbers in the bronchial mucosa (such changes cannot prove cause and effect but may provide mechanistic clues). In the event, we observed none. The study may not have been sufficiently powered to detect such changes. A further caveat is the issue of cell clusters. It was with great interest that we noted clusters of $\mathrm{CD} 38^{+}$plasmablasts and $\mathrm{CD} 20^{+} \mathrm{B}$ cells in approximately one in 10 sections of the bronchial mucosa, consistent with our previous observation that these cells switch locally to IgE synthesis [18]: this would likely be accompanied by multiple cellular divisions [36]. It is technically challenging to enumerate changes in numbers of cells distributed as discrete clusters. Even assuming, however, that omalizumab does also inhibit local B cell differentiation and IgE synthesis in the bronchial mucosa, consistent with its known effects on IgE expressing B cells and antigen-presenting cells [37, 38], it is again not yet clear if and why this may be important in asthma.

Designed as it was to provide proof of concept, the present study has limitations. The study was neither designed nor powered to detect influences of omalizumab therapy on "conventional" clinical outcomes; in particular, changes in quality of life or disease exacerbation rate. We were unable, as mentioned, to power the study for the proposed histopathological end points because of paucity of prior, relevant data and because of the difficulty of enumerating cells in clusters in very small samples of the bronchial mucosa.

Notwithstanding these observations, our findings and those of others referred to herein arguably merit closer examination of the therapeutic worth of anti-IgE therapies in non-atopic asthma in larger studies with conventional clinical outcomes, potentially addressing a large therapeutic need.

The greater challenge for the future will be to uncover further mechanisms whereby IgE can regulate the severity and stability of asthma, enabling more substantial appraisal of the likelihood that any given individual will respond clinically to anti-IgE therapy using criteria which extend beyond the boundaries of conventional atopic status. This is a key theme of our ongoing research.

\section{Acknowledgements}

The authors acknowledge the support and help of other members of the clinical research team including Kheem Jones, Helen Bull, Cherylin Reinholtz, May Rabuya, Leonard Siew and Victor Turcanu (all King's College London, London, UK). The authors also acknowledge the support from Ghada Eid, Jack Barker, Patrick White (all King's College London, London, UK) and Neil Barnes (Bart's Health NHS Trust, London, UK) at various stages of the study.

\section{References}

1 GINA Asthma Burden Summary. From the Global Strategy for Asthma Management and Prevention, Global Initiative for Asthma (GINA) 2014. www.ginasthma.org/2014 Date last accessed: 2016. Date last updated: 2014.

2 England HSF. Joint Health Surveys Unit, 2000; Census 2001 (Office for National Statistics: ONS) 2001. www.ucl. ac.uk/hssrg/studies/hse Date last accessed: 2016. Date last updated: 2010.

3 Diaz RA, Charles Z, George E, et al. NICE guidance on omalizumab for severe asthma. Lancet Respir Med 2013; 1: 189-190.

4 Humbert M, Busse W, Hanania NA, et al. Omalizumab in asthma: an update on recent developments. J Allergy Clin Immunol Pract 2014; 2: 525-536.

5 Eggel A, Baravalle G, Hobi G, et al. Accelerated dissociation of IgE-FceRI complexes by disruptive inhibitors actively desensitizes allergic effector cells. J Allergy Clin Immunol 2014; 133: 1709-1719.

6 Humbert M, Beasley R, Ayres J, et al. Benefits of omalizumab as add-on therapy in patients with severe persistent asthma who are inadequately controlled despite best available therapy (GINA 2002 step 4 treatment): INNOVATE. Allergy 2005; 60: 309-316.

7 The ENFUMOSA cross-sectional European multicentre study of the clinical phenotype of chronic severe asthma. European Network for Understanding Mechanisms of Severe Asthma. Eur Respir J 2003; 22: 470-477.

8 Moore WC, Meyers DA, Wenzel SE, et al. Identification of asthma phenotypes using cluster analysis in the Severe Asthma Research Program. Am J Respir Crit Care Med 2010; 181: 315-323.

9 Beeh KM, Ksoll M, Buhl R. Elevation of total serum immunoglobulin E is associated with asthma in nonallergic individuals. Eur Respir J 2000; 16: 609-614. 
10 Bentley AM, Durham SR, Kay AB. Comparison of the immunopathology of extrinsic, intrinsic and occupational asthma. J Investig Allergol Clin Immunol 1994; 4: 222-232.

11 Humbert M, Durham SR, Ying S, et al. IL-4 and IL-5 mRNA and protein in bronchial biopsies from patients with atopic and nonatopic asthma: evidence against "intrinsic" asthma being a distinct immunopathologic entity. Am J Respir Crit Care Med 1996; 154: 1497-1504.

12 Ying S, Humbert M, Barkans J, et al. Expression of IL-4 and IL-5 mRNA and protein product by CD4+ and CD8+ $\mathrm{T}$ cells, eosinophils, and mast cells in bronchial biopsies obtained from atopic and nonatopic (intrinsic) asthmatics. J Immunol 1997; 158: 3539-3544.

13 Humbert M, Durham SR, Kimmitt P, et al. Elevated expression of messenger ribonucleic acid encoding IL-13 in the bronchial mucosa of atopic and nonatopic subjects with asthma. J Allergy Clin Immunol 1997; 99: 657-665.

14 Kotsimbos TC, Ghaffar O, Minshall EM, et al. Expression of the IL-4 receptor alpha-subunit is increased in bronchial biopsy specimens from atopic and nonatopic asthmatic subjects. J Allergy Clin Immunol 1998; 102: 859-866.

15 Yasruel Z, Humbert M, Kotsimbos TC, et al. Membrane-bound and soluble alpha IL-5 receptor mRNA in the bronchial mucosa of atopic and nonatopic asthmatics. Am J Respir Crit Care Med 1997; 155: 1413-1418.

16 Humbert M, Ying S, Corrigan C, et al. Bronchial mucosal expression of the genes encoding chemokines RANTES and MCP-3 in symptomatic atopic and nonatopic asthmatics: relationship to the eosinophil-active cytokines interleukin (IL)-5, granulocyte macrophage-colony-stimulating factor, and IL-3. Am J Respir Cell Mol Biol 1997; 16: $1-8$.

17 Ying S, Meng Q, Zeibecoglou K, et al. Eosinophil chemotactic chemokines (eotaxin, eotaxin-2, RANTES, monocyte chemoattractant protein-3 (MCP-3), and MCP-4), and C-C chemokine receptor 3 expression in bronchial biopsies from atopic and nonatopic (Intrinsic) asthmatics. J Immunol 1999; 163: 6321-6329.

18 Takhar P, Corrigan CJ, Smurthwaite L, et al. Class switch recombination to IgE in the bronchial mucosa of atopic and nonatopic patients with asthma. J Allergy Clin Immunol 2007; 119: 213-218.

19 Ying S, Humbert M, Meng Q, et al. Local expression of epsilon germ line gene trancripts and RNA for the epsilon heavy chain of IgE in the bronchial mucosa in atopic and non-atopic asthma. J Allergy Clin Immunol 2000; 107: 686-692.

20 Humbert M, Grant JA, Taborda-Barata L, et al. High-affinity IgE receptor (FceRI)-bearing cells in bronchial biopsies from atopic and nonatopic asthma. Am J Respir Crit Care Med 1996; 153: 1931-1937.

21 Pillai P, Fang C, Chan YC, et al. Allergen-specific IgE is not detectable in the bronchial mucosa of nonatopic asthmatic patients. J Allergy Clin Immunol 2014; 133: 1770-1772.

22 Welliver RC. Respiratory syncytial virus and other respiratory viruses. Pediatr Infect Dis J 2003; 22: 2 Suppl., S6-S10.

23 Tomassen P, Jarvis D, Newson R, Van Ree R, et al. Staphylococcus aureus enterotoxin-specific IgE is associated with asthma in the general population: a GA(2)LEN study. Allergy 2013; 68: 1289-1297.

24 Kitaura J, Song J, Tsai M, et al. Evidence that IgE molecules mediate a spectrum of effects on mast cell survival and activation via aggregation of the FceRI. Proc Natl Acad Sci USA 2003; 100: 12911-12916.

25 Chan YC, Ramadani F, Santos AF, et al. "Auto-anti-IgE": Naturally occurring IgG anti-IgE antibodies may inhibit allergen-induced basophil activation. J Allergy Clin Immunol 2014; 134: 1394-1401.

26 Maurer D, Fiebiger S, Ebner C, et al. Peripheral blood dendritic cells express FceRI as a complex composed of FceRI $\alpha$ - and FcERI $\gamma$-chains and can use this receptor for IgE-mediated allergen presentation. J Immunol 1996; 157: 607-616.

27 Juniper EF, O'Byrne PM, Ferrie PJ, et al. Measuring asthma control. Clinic questionnaire or daily diary? Am J Respir Crit Care Med 2000; 162: 1330-1334.

28 Juniper EF, Guyatt GH, Cox FM, et al. Development and validation of the Mini Asthma Quality of Life Questionnaire. Eur Respir J 1999; 14: 32-38.

29 Garcia G, Magnan A, Chiron R, et al. A proof-of-concept, randomized, controlled trial of omalizumab in patients with severe, difficult-to-control, nonatopic asthma. Chest 2013; 144: 411-419.

30 MacGlashan DW Jr, Bochner BS, Adelman DC, et al. Down-regulation of FceRI expression on human basophils during in vivo treatment of atopic patients with anti-IgE antibody. J Immunol 1997; 158: 1438-1445.

31 Beck LA, Marcotte GV, MacGlashan D, et al. Omalizumab-induced reductions in mast cell FceRI expression and function. J Allergy Clin Immunol 2004; 114: 527-530.

32 Prussin C, Griffith DT, Boesel KM, et al. Omalizumab treatment downregulates dendritic cell FcepsilonRI expression. J Allergy Clin Immunol 2003; 112: 1147-1154.

33 Djukanović R, Wilson SJ, Kraft M, et al. Effects of treatment with anti-immunoglobulin E antibody omalizumab on airway inflammation in allergic asthma. Am J Respir Crit Care Med 2004; 170: 583-593.

34 Bousquet J, Rabe K, Chung KF, et al. Predicting and evaluating response to omalizumab in patients with severe allergic asthma. Respir Med 2007; 101: 1483-1492.

35 Chanez P, Contin-Bordes C, Garcia G, et al. Omalizumab-induced decrease of FcERI expression in patients with severe allergic asthma. Respir Med 2010; 104: 1608-1617.

36 Ramadani F, Upton N, Hobson P, et al. Intrinsic properties of germinal center-derived B cells promote their enhanced class switching to IgE. Allergy 2015; 70: 1269-1277.

37 Chan MA, Gigliotti NM, Dotson AL, et al. Omalizumab may decrease IgE synthesis by targeting membrane IgE+ human B cells. Clin Transl Allergy 2013; 3: 29.

38 Lowe PJ, Renard D. Omalizumab decreases IgE production in patients with allergic (IgE-mediated) asthma; PKPD analysis of a biomarker, total IgE. Br J Clin Pharmacol 2011; 72: 306-320. 